Alexander Burnasov, Maria Ilyushikina, Yuri Kovalev, Anatoly Stepanov

Ural Federal University, Yekaterinburg, Russia

\title{
Convergence and divergence processes in regional development
}

\begin{abstract}
The article deals with the basic trends of regions in the context of globalization and regionalization of the world's economy. The most important factors of regional development today are the innovation resource areas, their institutional environment, political regimes as well as regional policy, and geographical and socio-demographic factors.
\end{abstract}

Keywords: convergence; divergence; globalization; regional development

\section{INTRODUCTION}

One of the main features of the modern world economy is the retained spatial disparity of social and economic development of countries and world regions. Regional development is considered to be complex and contradictory. The creation of the working places and economic growth in particular regions may negatively influence the economic development of other territories. Globalization of the world economy intensifies the interaction and interdependence of its structures. New realities of the global world economy strain the international rivalry and make new demands to regional and national economic, social and political structures. The world is becoming "flatter" towards spatial mobility of various social organizations and people but, at the same time, it is becoming tougher on the social and economic levels of development.

Despite the policies of economic modernization carried out by the developing countries over the past sixty years, and the technological and expert assistance rendered to them by the U.N., the difference between developed and developing countries remains vast. On the macro-territorial level, the disparity in social and economic development is obvious if we compare such indicators as per capita income, infant mortality, life expectancy, etc. between "the core" and "the periphery" of the world economy. At the internal and regional level, the differences between developing and developed countries are still significant. 
Heterogeneity of spatial macrostructures is reflected in the models of a "trinomial world economy structure" (Mironenko, 2010) or in three "fields" of the modern world (Bolz, 2002). There are three fields of world community. The major part of the world community lives in a traditional society, that is to say the Third World, faced with the problems of migration and fundamentalism. In those countries, where nation-states are still trying to control the processes by means of tax policy, people live in modernity. "The world of the postmodern becomes apparent where the knowledge society is formed, where global players set the pace to the economy, where "smart cities" grow from the ground" (Bolz, 2002).

In spite of the economic dynamics in the developing countries over the last sixty years, the borders between the macrostructures of the world economy remain in place; only a small number of developing countries have successfully managed to change from the traditional community to postmodern - «new industrial countries» of the first generation. The social sectors of many developing countries are still in a pre-modern state. They are not traditional societies, because global mechanisms in the form of economic, cultural and social impact have changed traditional structures of a social system by creating western constructs such as healthcare systems, education, army, police, elites, which have a specific development in a traditional regional and social context. These factors prevent us from labeling such societies as traditional. Moreover, the main goal of modernization is to achieve the level of the developed countries, of which the major indicator is the economic growth, but this has given rise to the problems of asymmetric territorial development, vertical stratification of the population and the ecological problems in developing countries. Concentrated in some particular areas (big cities), economic growth has led to the polarization of regional development within states and increased disparity in the regions. As a result, these regions face problems such as unemployment, rural population outflow, infrastructure degradation, etc.

\section{Material AND METHOD}

Divergence on social and economic levels of regional development can be observed both in developing and developed countries. In many of them, globalization and the neoliberal development paradigm has caused income inequality and disparities in the living standards. "The Core" and "the Periphery" are now no longer separated as they were before. Significant differences in living standards in cosmopolitan cities are quite obvious. Indian economist S. Mehta comments on this fact: "The first and the third worlds are not two opposite blocs. On our planet «the North» and «the South» are close to each other, and collide inside one and the same city. There are men in Bombay so prosperous that they use laundries in Paris to wash their clothes. And, at the other extreme, the average lifetime of a person from Harlem is lower than in Bangladesh" (Mehta, 2006).

In developed countries with a social market economy, the disproportions in territorial development are demonstrated by the existence of dynamically developing regions with a high index of living standards and stable economic growth, and also regions with stagnating 
economies and acute social problems. Examples of such cases can be seen in South Italy, France with its Drome region, Lausitz in Germany, etc. National territorial polarization is not a new phenomenon, but it is nowadays present on a global scale. Regions with traditional industries weakly integrated into a global production system with locally oriented services and agriculture are characterized as regions of economic and social compression. Among them we can point out the socially and economically "unfavourable" territories with a high unemployment level, population outflow, abnormal criminal situation. Good examples of these are former industrial regions of Western Europe which have recently been dominant economic clusters. We consider some territories of Central and Eastern Europe to be regional outsiders as they are no longer attractive countries due to the occurrence of structural transformations. This is a new European Union periphery, regions in recession of the stagnation. We may find many more similar areas on the map, rather than prosperous regions. A clear example is the majority of territories of the former German Democratic Republic. Mass migration to western lands (more than 2 million people over the period of 1990-2010), high unemployment level (14\% in the year 2010$)$, low birth rate $(0.8 \%)$, and the disappearance of villages are typical modern features of Eastern Germany. "In Western Germany people complain about the conditions of a society in which only two thirds of the population live in prosperity, but at the same time a society with two thirds its people living in poverty exists in Eastern Germany" (Gensichen, 2007: 112).

On the contrary, new developing regions with high integration into the production and service nets, focusing on highly technological manufacturing, highly qualified personnel and new life style emerge. They are characterized by high incomes, high living standards, low unemployment and migration levels, good social infrastructure. These are the regions with high social and national heterogeneity. Due to a concentration of science-oriented branches of industry a new type of society is formed, a society with its people involved in generating technical and social innovations in economic sphere. In sociological literature such type of society is called the knowledge society, cognitive capitalism, Wissensgesellschaft. We can identify them as regions of the third technological revolution in which our future is made (Toffler, Rifkin).

\section{FINDING}

The reasons for the economic progress or recession can be explained by the theoretical conceptions of economic growth and development. Classical theories throw light on the differences between economic and social development by showing unsteady spatial labour force assignment and capital distribution. Labour and capital are considered to be the main factors of productivity and economic growth. New growth theories are based on the universal positions, which state that the reasons for economic growth and regional stagnation can not only be explained from the perspective of spatial labour and capital differentiation. Labour and capital are flexible and may transform from one standard to another in modern 
global economy. Innovative resources within the territories, their institutional sphere, political regimes, geographic and demographic factors are the key factors of regional development nowadays.

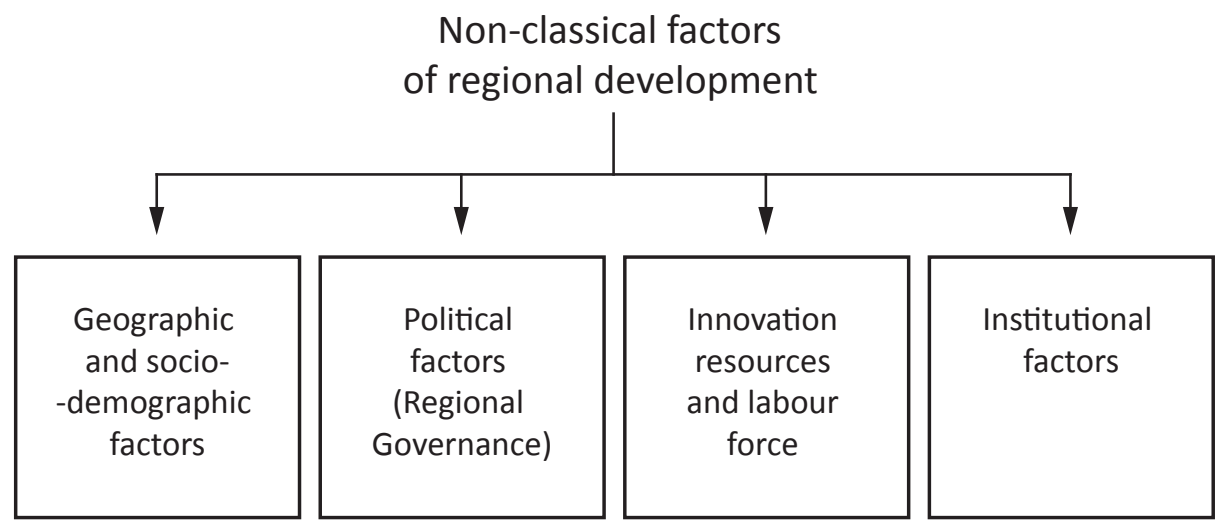

Source: authors' research projects

The first group of growth factors includes "natural" conditions of the territories: geographic location, natural resources, climate and socio-demographic situation. Countries and regions with favourable geographic location, climate and population density have a higher productivity and growth pace than the territories with opposite characteristics. Ethnic, religious and linguistic fragmentations are the main constraints to high population growth.

The second category of factors considers regional political systems and economic policies of a particular region. Regional agriculture, stable prices, effective management policy, social stability in a region is favourable for regional development. The effect of non-democratic regimes may be quite contradictory (although some authors have pointed out the ambiguity of this factor and provide examples of economic growth in countries with authoritarian regimes such as Brazil, Singapore and Chile), and it is worth considering that the consolidation of the political and economic elites form obstacles to various reforms and innovations, as does corruption and interference of the state into the economy of the country and the public life.

The third group of factors describes the institutional sphere in the region, the laws, rules, and norms typical to the particular society, on the basis of which people live and interact with each other. The existence of the institutional sphere helps minimize the risks and reduces expenses on the data ware of organizations, and individuals as people are aware of the rules, norms and values typical of the regional society.

We are going to describe in detail the fourth category of factors which influence regional development. The investigation of economic and technological development interaction has a long history. For the last hundred years the role of technological innovation in economic development has been demonstrated in research by I. Shumpeter (1911), Kondratyev (1926), R. Soloy (1956), A. Khirshman (1967), P. Romer (1990) and others. In the 1980s and 
1990s topics connected to the specific features of spatial production and innovation diffusion were dominant in the scientific discourse on innovative development. Research work was concentrated on studying various regional factors which influence the innovation generation within the territorial frame conditions. We should mention studies on national innovation systems (Lundval, 1992; Nelson and Rozenberg, 1993), which throw light on differences in the development levels of an innovation complex between countries with unequal institutional conditions, various resource indices, and interaction between governmental, private and public structures. According to these, the development of national innovation systems depends on the presence of certain endogenous factors, of which state technological policy is the most important. The idea of a national innovative system is applicable for the investigation of geographic features of innovation processes on the macro territorial level.

In the 1990s, works on regional innovative systems appeared within the theory about national innovative systems (Lundval, 1992; Avtio, 1998; Cook, 2000). They were focused on the regional differences in the development of the innovative activities within the political and administrative state borders. The main reason for spatial asymmetry is in the territorial differences in the production development of a particular country. Tacit knowledge has an influence on the spatial location of innovative actors as well as on their concentration in certain areas. Such system of knowledge transfer is only possible at the level of personal communication based on common goals and mutual trust. It is in turn real only when actors are territorially close to each other and the opportunity for a communication between them exists. The tacit knowledge possessed by regional institutions can serve as a counter-balance to global trends and as a factor of spatial regionalization.

Since the 1990s the influence of innovative factors on regional development has become universally recognized. Grossman and Helpman came to the conclusion based on their own research, that technical progress as an investment in technological knowledge forms about $50 \%$ of regional economic growth, but the question about the most effective forms of innovation in regional development and their possible implementation in other regional systems is still open (Grossman, Helpman, 1991).

\section{Conclusion}

Some scientists point out not only the importance of technical innovations for regional development, but also the meaning of innovation as new applied knowledge in the wider sense of this word. Producing, introducing and implementing knowledge by way of innovation in management, social, and other spheres, is necessary for successful regional development. The technical knowledge is not the only critical factor for a the development of the human potential of the region, the level of education and intellectual competence, creativity and experience are also the main criteria for regional prosperit (Gorz, 2005: 19). Constant regional renewal and compliance with world standards is possible only where there is permanent endogenous knowledge production and innovation adaptation. 
The role of "innovation factor" and its interrelation with other growth factors in regional development is considered by many specialists as determinant for transformation to a knowledge society. Innovation production forms the basis for postindustrial society of knowledge. The knowledge society is centred on innovation and the one in which regional development and social, economic, and political competitiveness are hardly possible if this is absent. Taking into account the dominant role of knowledge and innovation in its development we have found that, in regions, the knowledge society is formed out of innovation.

\section{References}

Bolz, N. (2002). "Celebrity Design" und "Muddling through". Die zwei Gesichter der postmodernen Politik. Forschung \& Lehre, 8, 415-416.

Gensichen, H.P. (2007). Uckermark. Zukunftsroman. Mit einem Essay Chancen des Schrumpfens. Wittenberg: Eigenverlag.

Gorz, A. (2005). Wissem, Wert und Kapital: Zur Kritik der Wissensokonomie. Zürich: Rotpunktverlag. Grossman, G., Helpman, E. (1991). Innovation and Growth in the Global Economy. Cambridge: Mit Press.

Mehta, S. (2006). Metropole Bombay, Zukunft der Welt. Atlas der Globalisierung, Edited by A. Gresh, Berlin: TAZ. 190-191.

Mironenko, N.S. (2010). Main features of a spatial structure of world economy as a system, Regional Research, 4, 3-13.

Alexander Burnasov, Ph.D. in History, Ural Federal University, Institute of Social and Political Sciences, Department of Regional Research, Yekaterinburg, Russia.

Russia. The development of transport logistics in the context of globalization. International communication and international cooperation, interests - history,economy, logistics, globalization.

e-mail: burnasov@mail.ru

Maria Ilyushkina, Ph.D. in Philology, Ural Federal University, Institute of Social and Political Sciences, Department of Regional Research, Yekaterinburg, Russia.

Cross-cultural communication, interests - linguistics, world economy and cultures.

e-mail: ilyushkina_maria@mail.ru

Yuri Kovalev, Ph.D. in Geography, Ural Federal University, Institute of Social and Political Sciences, Department of Regional Research, Yekaterinburg, Russia.

Innovative regions of the world. The processes of convergence and divergence in the world economy. Problems of modern economic geography, interests - economic geography, world civilizations.

e-mail: ykowaljow@pochta.ru

Anatoly Stepanov, Ph.D. in geography, Ural Federal University, Institute of Social and Political Sciences, Department of Regional Research, Yekaterinburg, Russia.

Russia. Socio-economic asymmetry in the economic development of the regions. The impact of globalization on the transformation of the regions. The theory of clusters and cluster strategies, interests - world economy, globalization, cluster policy, economic geography.

e-mail: anatoly_stepanow@mail.ru

\section{Adres/address:}

Ural Federal University, Yekaterinburg, Russia, 620083 Russia, Yekaterinburg, Lenin Avenue, 51 